\title{
Renal Function Reserve in Chronic Obstructive Pulmonary Disease with Type II Respiratory Failure
}

\author{
Manal Mahmoud*, Nesriene El Margoushy**, Hassan Shalby* and Aya M. \\ Abdel Dayem***. \\ Medicine Dept., Faculty of Medicine, Ain Shams University* Medical and Radiation Research \\ Dept. ,Nuclear Materials Authority** Chest Dept., Faculty of Medicine, \\ Ain Shams University***.
}

\begin{abstract}
Background and objective: increase in renal blood flow in response to certain stimuli such as dopamine infusion, oral protein load, and amino acid infusion. Reduced or absent renal functional reserve (RFR) is an early index of renal impairment. Our work studies the (RFR) in Chronic Obstructive Pulmonary Disease (COPD) patients with chronic compensated type II respiratory failure.

Methods: Our study included 15 COPD patients with compensated type II respiratory failure and 5 normal controls. The patient group had mean $\mathrm{Pa} \mathrm{O}_{2} 56.5 \pm 6.4$ and $\mathrm{Pa} \mathrm{CO}_{2}$ 56.5 \pm 3.2 , while in normal controls the mean $\mathrm{Pa} \mathrm{O}_{2}$ was $97.4 \pm 0.3$ and $\mathrm{Pa}_{\mathrm{CO}_{2}}$ was $42.3 \pm 1.2$. Hypoxic patients $\left(\mathrm{Pa}_{2}<\right.$ or $\left.=59 \mathrm{~mm} \mathrm{Hg}\right)$ allowed to receive low flow oxygen by nasal prongs to keep their $\mathrm{Pa} \mathrm{O}_{2}>$ or $=60 \mathrm{~mm} \mathrm{Hg}$ and $\mathrm{Sa}_{2}>$ or $=90 \%$ without rise of $\mathrm{PaCO}_{2}$ within 2 hours before and during the study. The pulsatility index (PI), an index of reno-vascular resistance (RVR), was measured non invasively by Doppler Ultrasonograghy at baseline and 20 minutes after infusion of dopamine in diuretic dose.

Results: The baseline PI was nearly similar in the control group and in COPD patients (no significant difference), the PI fell significantly in the control group after dopamine infusion from $1.03 \pm 0.14$ to $0.83 \pm 0.1(\mathrm{P}<0.05)$, but increased significantly in COPD patients from 1.02 \pm 0.12 to1.18 $\pm 0.13(\mathrm{P}<0.05)$ after dopamine infusion.

Conclusion: Renal functional reserve is impaired in hypercapnic COPD patients and this may be a factor in the development of edema frequently seen in these patients.
\end{abstract}

\section{Introduction}

Renal haemodynamics are affected by changes in arterial oxygen $\left(\mathrm{O}_{2)}\right.$ and carbon dioxide $\left(\mathrm{CO}_{2}\right)$. This has been well documented in patients with Chronic Obstructive Pulmonary Disease (COPD), especially during an acute exacerbation (MacNee, 1994). For several years water retention and hyponatraemia were typically observed in the final stages of (COPD) and the onset of edema was a poor prognostic factor. It was originally hypothesized that these patients had right ventricular failure secondary to pulmonary hypertension as a consequence of hypoxia induced pulmonary vasoconstriction, however in the absence of primary cardiac disease, most COPD patients had normal or even increased cardiac output (COP) (Compbell and Short, 1960). It now seems that the pathogenesis of edema in these patients would be correlated with gas exchange impairment and in particular with carbon dioxide $(\mathrm{CO} 2)$ retention. The gas exchange impairment induces, in these patients several hormonal abnormalities: renin (Rn), angiotensin II (AnII), aldosterone (Ald), atrial natriuretic peptide (ANP) and vasopressin (ADH). The systemic response to hypercapnia has effect in renal haemodynamic by reducing the renal blood flow and, as a result, increasing water and sodium retention with the final effect of edema and hyponatraemia which observed in the final stage of COPD (Valli et al., 2004). 
Most patients with COPD, even those with edema, have normal serum creatinine with a normal or only slightly reduced glomerular filtration rate (GFR). It is known that kidney has the ability to increase the GFR and the renal blood flow (RBF) in response to certain stimuli such as an oral protein load, amino acid infusion and dopamine in vasodilator or diuretic dose (Ter Wee et al., 1986). This phenomenon is known as the renal functional reserve (RFR), and is defined as the difference between the base line GFR and or RBF and the maximum value after using one of such methods (Memoli et al., 1991). There is no constant value for the RFR as it has been shown to vary between $10 \%$ and $70 \%$ of the base line GFR (Ter Wee et al., 1985).

The pulsatility Index (PI) is an index of resistance to flow in vascular beds distal to the point of sampling, thus it is an indirect index of the degree of vasoconstriction. It can be measured non-invasively by Doppler ultrasonography (Rourke et al., 2006).

\section{Aim of the work}

The aim of this work is to study RFR in COPD patients with chronic compensated type II (hypercapnic) respiratory failure.

\section{Patients and Methods}

Fifteen patients (all males) with chronic compensated type II respiratory failure were included in the study. They fulfilled the American Thoracic Society criteria for diagnosis of COPD, and had no acute exacerbation. They were all current or previous cigarette smokers. All of them had a history of lower limb edema, although only 5 had current edema. All subjects had $\mathrm{FEV}_{1}$ (forced expiratory volume in first second) values of less than 1 liter and $\mathrm{PaCO}_{2}>47 \mathrm{~mm} \mathrm{Hg}$. Clinical examination and biochemical tests showed no evidence of Diabetes Mellitus (DM), renal disease or liver disease. ECG was done to all cases and echocardiography to some cases to exclude significant arrhythmias, left ventri- cular failure and ischemic heart disease. All patients were receiving theophylline orally with inhaled salbutamol. Ten patients were receiving inhaled ipratropium bromide, while 8 patients were receiving inhaled steroids. None of the patients were receiving oral diuretics and 7 patients were receiving Angiotensin Converting Enzyme inhibitors (ACE). All medications were stopped 24 hours before the study except inhaled bronchodilators. Hypoxic patients $\left(\mathrm{PaO}_{2}=\right.$ or $\left.<59 \mathrm{mmHg}\right)$ allowed to receive low flow oxygen by nasal prongs to keep their $\mathrm{Pa} \mathrm{O}_{2}=$ or $>60 \mathrm{~mm} \mathrm{Hg}$ and $\mathrm{SaO}_{2}>$ $90 \%$ without rise of $\mathrm{PaCO}_{2}$ within 2 hours before and during the study.

Five healthy volunteers were recruited from hospital staff. All of them were not receiving any medication.

After taking verbal consent, all subjects were studied nearly in the same time (between 12:30 to 2:30 p.m.). They were fasting for the last 6 hours before the study, and subjected to the following:

\section{Ultrasonography:}

Recording was made while they lay in a half supine position. We used a real time ultrasound scanner (model: HEWLETT PACKARD [hp] SONOS 100077025 SA ultrasound system color duplex using convex $2.5 \mathrm{MHz}$ probe) with color flow and pulsed scanning facility. Both kidneys were scanned via the translumbar route. A renal interlobar artery was selected near the renal hilum. The angle of the US beam was adjusted until the maximum Doppler frequency shift was obtained. From that sonogram, the integrated computer software calculated the PI. The PI is an indirect but sensitive index of the degree of vasoconstriction. The lower the PI, the less the resistance to flow (Rourke et al., 2006). We take the mean of 3 measurements. Cases with significant difference in their PI between the 2 kidneys were excluded.

\section{Dopamine Infusion:}

Dopamine hydrochloride, diluted in $5 \%$ dextrose solution was given by IV infusion through solu-set in a dose rate of 2 $\mathrm{ug} / \mathrm{kg} / \mathrm{min}$. (diuretic or renal vasodilator dose). PI was measured 20 minutes after the 


\section{Manal Mahmoud et al}

start of dopamine infusion. Arterial sample was withdrawn from all subjects immediately before the study. We record both the pulse rate and the arterial blood pressure throughout the study.

\section{Results}

The study included 15 COPD patients with compensated chronic type II respiratory failure and 5 normal controls. All subjects were men. The mean age, $\mathrm{FEV}_{1}$ and Arterial Blood Gas (ABG) from patients and controls are given in table (1).

Renal response to Dopamine Infusion

The baseline PI was nearly similar in the control group and in the COPD patients (no significant difference). In normal controls the PI fell significantly after dopamine infusion by $0.2(24 \%)(\mathrm{p}<0.05)$, which means that the resistance to renal blood flow decreased in normal controls after dopamine infusion (Table 2, Graph 1). In COPD patients the PI rose significantly by $0.16(15.6 \%)(\mathrm{p}<0.05)$, which means that the resistance to renal blood flow increased in these patients after the use of dopamine infusion ( Table 2, Graph 1 ) .

$\mathrm{P}<0.05$, i.e., there was a statistical significant difference in PI before and after dopamine infusion in the COPD and control groups

Table (1): Showing the mean age, $\mathrm{FEV}_{1}, \mathrm{PaO}_{2}$ and $\mathrm{Pa} \mathrm{CO}_{2}$ in $\mathrm{COPD}$ patients and control group.

$\begin{array}{lc} & \mathrm{COPD} \\ & (\mathrm{N}=15) \\ \mathrm{Age} \text { ( years ) } & 52.4 \pm 5.6 \\ \mathrm{FEV}_{1} \text { (Liters) } & 0.85 \pm 2.1 \\ \mathrm{PaO}_{2} \text { (room air ) ( mmHg) } & 56.5 \pm 6.4 \\ \mathrm{PaCO}_{2} \text { (mmHg) } & 56.5 \pm 3.2\end{array}$

Controls
$(\mathrm{N}=5)$
$38.2 \pm 4.5$
$3.2 \pm 0.6$
$97.4 \pm 0.3$
$42.3 \pm 1.2$

Table (2): Showing the PI before and after dopamine infusion in COPD patients and the normal control group.

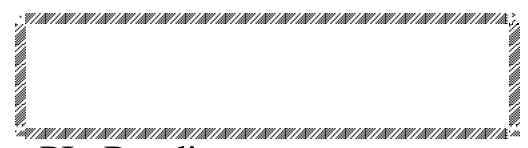

PI : Baseline

PI : After dopamine

$P$ value

\section{COPD}

$1.02 \pm 0.12^{*}$

$1.18 \pm 0.13$

$(<0.05)$
Controls

$1.03 \pm 0.14^{*}$

$0.83 \pm 0.13$

$(<0.05)$

$*=\mathrm{P}>0.05$, i.e., there was no difference in baseline PI between patients and controls. 


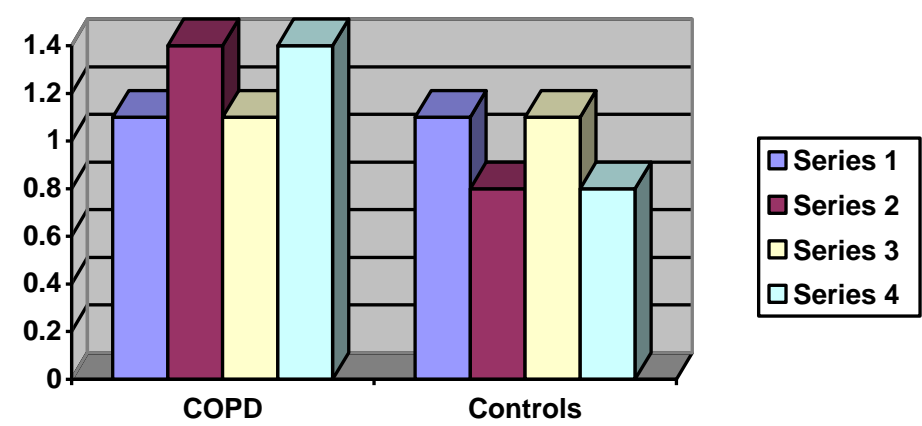

\section{Graph (1) : PI in COPD patients and Normal Controls}

\section{Discussion}

A reduction in renal blood flow has been consistently reported in patients with chronic respiratory failure from COPD. A fall in flow occurs during edematous exacerbation when Arterial Blood Gas (ABG) tensions worsen and then partially improve after recovery but remain chronically depressed (Howest et al., 1995).

Lima et al. (2005) studied the effect of $\mathrm{O}_{2}$ therapy in renal haemodynamic and excretion of sodium and water in COPD patients; they concluded that the use of oxygen caused increases of $36 \%$ in GFR, $35 \%$ in filtered load of sodium, $118 \%$ in diuresis, and $258 \%$ in excreted load of sodium. These data suggest that oxygeninduced natriuresis and diuresis were likely more dependent of changes in the tubular manipulation of sodium than in glomerular haemodynamics. These changes occurred with a mild increase in $\mathrm{PaCO} 2$, showing that oxygen therapy caused renal improvement independently of amelioration of hypercapnia.

The preservation of GFR in the face of the fall in RBF reduces renal filtration fraction and causes sodium and water retention by the kidney.

This mechanism is likely to be important in the excessive fluid retention that is a feature of these patients, but the cause of the reduction in RBF is unknown. COP is normal or even raised in COPD patients, and the fall in RBF therefore represents a rise in renal vascular resistance (RVR) (Amiel et al., 1990).
Studies on normal subjects have generally shown an increase in RBF with moderate acute hypoxemia, probably because of increased catecholamine concentrations and COP. Paradoxically, RBF is low in chronic hypoxemia as in patients with COPD despite of normal or even increased COP (Baudouin et al., 1992).

Sharkey et al. (1999); studied the acute effects of oxygen and $\mathrm{CO}_{2}$ on renal vascular resistance using the PI in COPD patients, the study included 40 COPD patients with chronic type II respiratory failure, their mean $\mathrm{Pa} \mathrm{O}_{2}$ was $54 \pm 8.8$ and $\mathrm{Pa} \mathrm{CO}_{2}$ was $54.8 \pm 8.8 \mathrm{Hg}$, they found significant decrease in PI (increased RBF) when they gave their patients oxygen to raise $\mathrm{Sa} \mathrm{O}_{2}$ to approximately $95 \%$, started after 10 minutes, the PI fell further from room air values when $\mathrm{Sa} \mathrm{O}_{2}$ was increased to $98 \%$ or to $99 \%$ (hyperoxemia; $\mathrm{P}<0.05$ ), while the end tidal $\mathrm{CO}_{2}$ did not change significantly, this suggests that RVR decreased with improved oxygenation, they gave their patients $\mathrm{CO}_{2}$ by inhalation, this acute rise in $\mathrm{Pa} \quad \mathrm{CO}_{2}$ lead to highly significant rise in PI (decreased RBF ) even when hyperoxemia is maintained, and this suggests that acute changes in $\mathrm{CO}_{2}$ levels might have a more dominant role than $\mathrm{O}_{2}$ levels in determining RVR.

The mechanism whereby hypoxemia affects renal haemodyanmics is not fully understood. In animal studies, changes in RBF secondary to hypoxemia are abolished by the denervation of the peripheral 


\section{Manal Mahmoud et al}

chemoreceptors, and are attenuated by renal denervation but not influenced by adrenalectomy, this suggests that changes in $\mathrm{RBF}$ are caused by a reflex mechanism that is dependent on the sympathetic afferent nerves to the kidney and chemoreceptor stimulation (Wang et al., 2005).

Sharkey et al. (1998); studied a group of normal and renal transplant subjects (with denervated kidneys) and measured their RVR in response to hypoxemia, they found that renal denervation did not completely abolish the reno-vascular response to hypoxemia.

Nitric oxide (NO) may also have a role in the renal haemodynamic response to hypoxemia. Howest et al. (1996); found that hypoxemic COPD patients were unresponsive to L-arginine, a NO precursor, while L-arginine caused renal vasodilatation in normal subjects; therefore, concluded that the disturbance in reno-vascular tone seen in hypoxemic COPD patients may be due to disturbance of the NO pathway.

In our study we tried to study the effect of chronic hypercapnia on RBF in COPD patients with compensated type II respiratory failure, from the previous studies we concluded that the effect of hypoxemia on $\mathrm{RBF}$ is reversible by giving those patients oxygen. So, in our COPD patients we gave them oxygen 2 hours before and throughout the study to keep their $\mathrm{PaO}_{2}$ above $60 \mathrm{~mm} \mathrm{Hg}$, and their $\mathrm{SaO}_{2}$ above $90 \%$.

In our study the baseline PI was similar in COPD patients and in the normal subjects, with dopamine infusion (in renal vasodilator dose ) we found a significant decrease in PI in normal controls, but we did not found decrease in PI in our COPD patients, but conversely we find significant increase in PI, i.e. there was an increase in RVR with dopamine infusion.

The fall in PI in our control subjects suggests that they had renal vasodilation following dopamine infusion, while the hypercapnic COPD patients had increased vasoconstriction after dopamine infusion even after correction of hypoxemia. Reduced renal functional reserve suggests an inability to increase RBF, and such patients may be more prone to reduced $\mathrm{RBF}$ during acute exacerbation with development of frank edema.

Our results agree with Sharkey et al. (1997); who studied renal functional reserve in patients with COPD, he also measured the PI by Doppler ultrasonography after giving the patients a protein load of $250 \mathrm{~g}$ steak (another method for measuring RFR), the PI fell significantly after the protein load in the normal subjects, in hypercapnic COPD patients, the PI rose after protein load to approach a statistical significant $(\mathrm{p}=0.06)$.

Howest et al. (1996); in an ultrasound study of patients with stable COPD, found that hypercapnic patients had reduced RBF while the RBF was similar in normocapnic patients and normal controls. However, in our study we found non significant differences in baseline renal haemodynamics between the patients with COPD and the controls, possibly because our COPD patients had less severe respiratory failure with mean $\mathrm{Pa}_{2} 56.5 \pm 6.4$ and mean $\mathrm{Pa}$ $\mathrm{CO}_{2} 56.5 \pm 3.2$.

Howest et al. (1995); found significant improvement of RBF in hypoxemic normocapnic COPD patients after dopamine infusion in diuretic dose as well as after oxygen therapy with no significant difference between the two modalities, and the effect of both together was not additive, this was not accompanied by any increase in COP measuring aortic blood flow. On the other hand, neither dopamine infusion nor oxygen improved RBF in hypoxemic hypercapnic patients, even when adding both modalities together and this agree with our results.

Hypercapnia can reduce renal blood flow by several mechanisms. Firstly, it may cause direct renal vasoconstriction. Secondry, hypercapnia causes peripheral vasodilatation which inactivates the baroreceptors with subsequent noradrenaline release which causes reduced RBF. Hypercapnia also increases noradrenaline levels by direct central sympathetic stimulation (Sharakey et al., 1998).

The mechanisms causing edema in COPD are not fully known. Early studies proposed that the edema was simply due to right ventricular failure secondary to 
hypoxemic pulmonary hypertension. A review of 150 cases of COPD patients found that most of patients with edema had hypercapnia, this leads to respiratory acidosis, with chronicity the kidney compensate by increasing tubular exchange of hydrogen ion for sodium and reabsorption of bicarbonates, leading eventually to fluid retention (Compbell and Short, 1960). Now with the proven decreased RBF in hypercapnic COPD, this can activates the rennin-angiotensin activating system, increasing plasma aldosterone levels with further sodium and water retention. Levels of antidiuretic hormone are also often inappropriately high in COPD patients with edema (Chabot et al., 1995).

There is no constant relationship between the GFR and change in the renal functional reserve; the renal functional reserve may be decreased before any change occurs in GFR, or it may fall linearly or variably with the GFR (Amiel et al., 1990). Therefore, the impairment of renal functional reserve we found in our study in COPD hypercapnic patients may be an early indication of impaired renal function.

Although our results are not concerned with chronic use of ACE inhibitor or renal vasodilator, Valli et al. (2004); showed that chronic use of ACE inhibitors in patients with COPD cause small but significant increase in effective renal blood flow while having no effect on the GFR. In our study we had 7 patients were receiving ACE inhibitors but we stopped it 24 hours before the study.

From our study and the previous studies we concluded that COPD patients have impairment in their reno-vascular haemodynamics in the form of impaired renal function reserve. In normocapnic hypoxic patients this effect may be reversed by oxygen or dopamine in diuretic dose, therefore these modalities could be effective in the treatment of intractable fluid overload in cor-pulmonale by increasing RBF; promoting diuresis and natriuresis; but in hypercapnic patients the renal vascular resistance even increase with such modalities. Therefore therapies that simultaneously correct both blood gas abnormalities (such as non invasive ventilation) might be more effective in the treatment of cor-pulmonale than oxygen therapy alone in such patients.

From our study, we recommend that (1): avoid conditions which may increase renal vascular resistance in hypercapnic COPD patients, as dopamine infusions in diuretic dose and high protein diet, especially during acute exacerbations and till correcting $\mathrm{Pa} \mathrm{CO}_{2}$ levels by mechanical ventilation, to avoid acute renal damage (2)Further studies are needed to show the effect of long term use of some drugs as ACE inhibitors and other renal vasodirators on renal functional reserve of such patients and if they have any beneficial effect or not.

\section{References}

1. Amiel C, Blanchet F, Freidlander G, Ni- tenberg A (1990): Renal functional reserve. Nephrol. Dial. Transplant, 5: 76370.

2. Baudouin SV, Bott J, Ward A (1992): Short -term effect of oxygen on renal haemodynamics in patients with hypoxaemic COPD. Thorax 47:550-554.

3. Chabot F, Mertes PM, Delorme N, Schrijen FV, Saunier CG, Polu JM (1995): Effect of acute hypercapnia on alpha atrial natriuretic peptide, rennin, angiotensin II, aldosterone, and vasopressin plasma levels in patients with COPD. Chest, 107; 680-6.

4. Compbell EJM and Short DS (1960): The cause of edema in corpulmonale. Lancet, I: 1184-6.

5. Howest TQ, Deane CR, Levin GE, Baudouin SV, Moxham J (1995): The effect of oxygen and dopamine on renal and aortic blood flow in COPD with hypoxemia and hypercapnia. Am.J. Respir. Crit. Care. Med., 151:378-383.

6. Howest TQ, Keilty SEJ, Maskrey VL, Deane CR, Baudouin SV, Moxham J (1996): Effect of L-arginine on renal blood flow in normal subjects and patients with hypoxic COPD. Thorax, 51:516-519.

7. Lima MR, Burdmann EA, Cipullo JP (2005): Oxygen therapy improves renal function in patients with chronic obstructive pulmonary disease. Ren Fail., 27(4):373-9 


\section{Manal Mahmoud et al}

8. MacNee W (1994): Pathophisiology of cor pulmonale in COPD: parts $1 \& 2$. Am.J.Respir, Crit ,Care Med., 150:833852, 1158-1168.

9. Memoli B, Libetta C, Sabbatini M, Conte G, Russo D, Giani U (1991): Renal functional reserve: its significance in normal and salt depletion conditions. Kidney Int., 40:1134-40.

10. Rourke C, Hendrickx P, Roth U, Brassel F, Creutzig A, Alexander K. (2006): Color and conventional imagedirected ultrasonography: accuracy and sources of error in quantitative blood flow measurement. J., Clin, Ultrasound, 20: 187-93.

11. Sharkey RA, Mulloy EMT, Kilgallen IA (1997): Renal function reserve in patients with severe chronic obstructive pulmonary disease. Thorax, 52:411-415.

12. Sharkey RA, Mulloy EMT, and O'Neill SJ (1998): The effects of hypoxemia, hyperoxaemia and hypercapnia on renal blood flow in normal and renal transplant subjects. Eur. Respir. J., 12:653-657.
13. Sharkey RA, Mulloy EMT, and O'Neill SJ (1999): The acute effects of oxygen and carbon dioxide on renal vascular resistance in patients with an acute exacerbation of COPD. Chest., 115:1588-92.

14. Ter Wee PM, Geerling W, Rosman JB, Sluiter WJ, Geet S, Donker AJM ( 1985 ): Testing renal reserve filtration capacity with an amino acid solution. Nephron, 41:103-9

15. Ter Wee PM, Smit AJ, Rosman JB, Sluiter WJ, Donker AJM (1986): Effect of intravenous infusion of low-dose dopamine on renal function in normal individuals and in patients with renal disease. Am.j.Nephrol., 6:42-6.

16. Valli G, Fedeli A, Antonucci R, Paoletti $\mathbf{P}$, Palange $\mathbf{P}$ (2004): Water and sodium imbalance in COPD patients. Monaldi Arch Chest Dis., 61(2):112-6.

17. Wang T, Kobayashi Y, Nabika T, Takabatake T (2005): Enhanced sympathetic control of renal function in rats congenic for the hypertension-related region on chromosome 1.Clin Exp Pharmacol. Physiol., 32(12):1055-60. 


\section{احتفاظ الكلى بوظائفها فى مرض السدة الرئوية المزمنة المصاحبة للاتزان المزمن للفشل التففى (النوع الثانى)}

منـال محمود قسم * / نسرين المرجوشى *** /حسن شلبى*** /أيسة

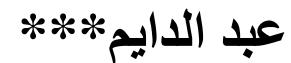
أمر اض باطنة كلية الطب جامعة عين شمس * ـ قسم البحوث الطبية و الإشعاعية هيئة

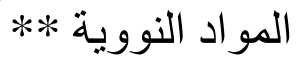

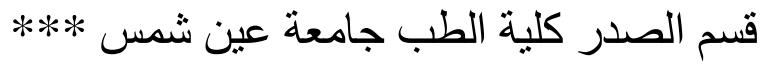

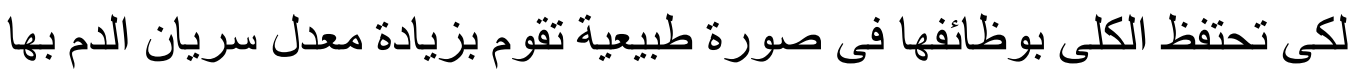

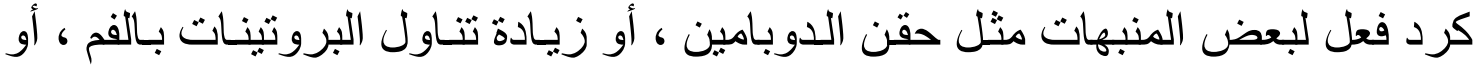

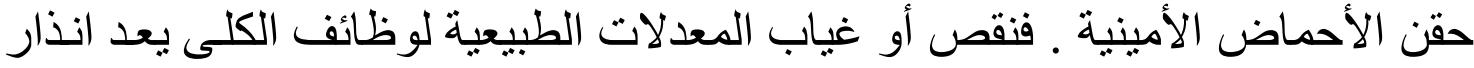

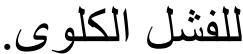

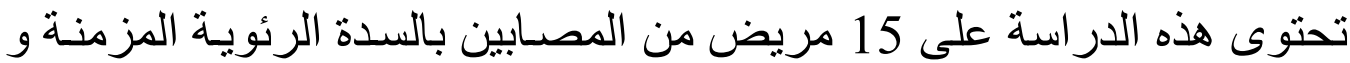

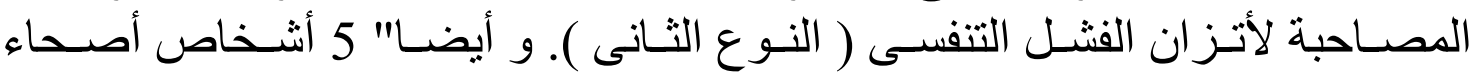
كمجمو عة ضابطة .

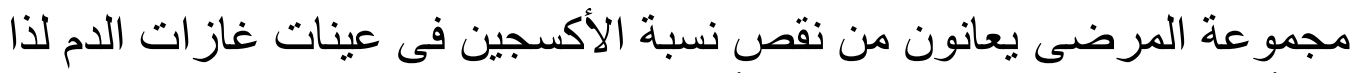

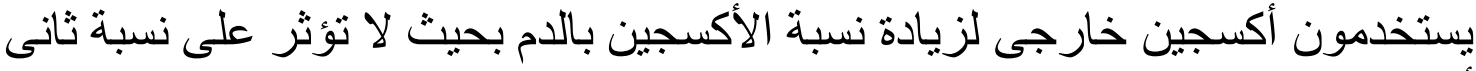

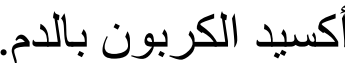

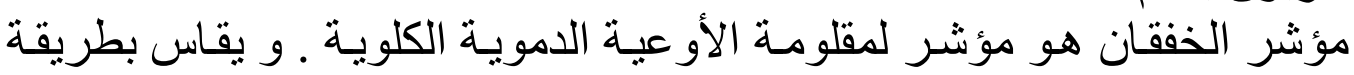

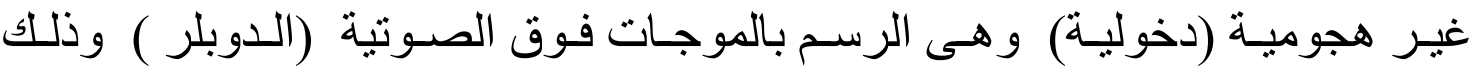

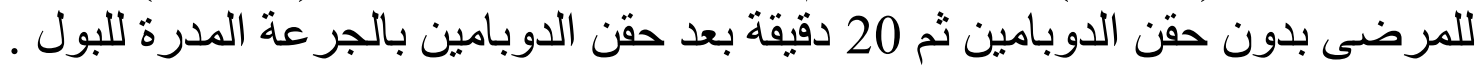
وقد نتج عن ذلك :-

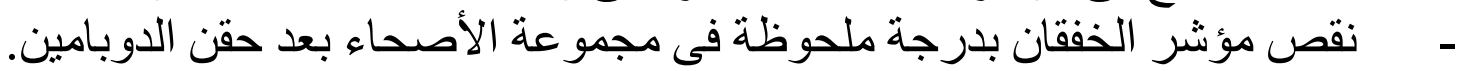

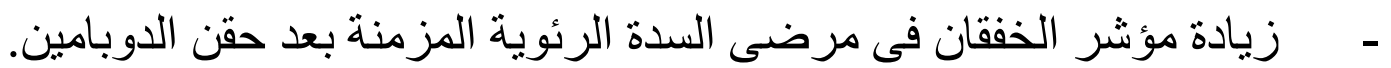

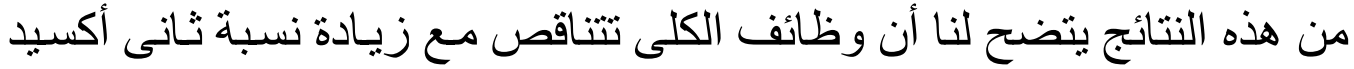

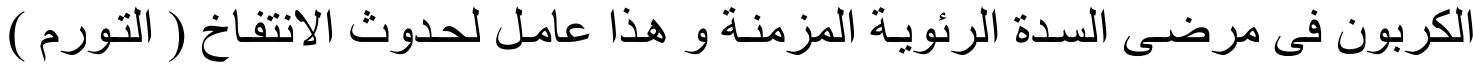

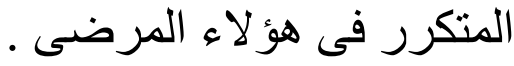

